\title{
Fazendas de gado no Paraná escravista
}

\section{Horacio Gutiérrez}

Os mercados internos começaram a se consolidar no Brasil no século XVIII com o deslocamento da economia para o Sudeste e a necessidade de abastecer de mantimentos as Minas Gerais. O fluxo comercial de alimentos, no entanto, sempre existiu, antes e depois desse período, em Minas e em outras províncias, e foi o resultado da especialização econômica na produção de poucos bens por parte das grandes unidades produtoras de artigos de exportação, como os engenhos de açúcar. No desenvolvimento desses circuitos mercantis a pecuária teve um papel central, como setor fornecedor do único meio de transporte disponível antes da construção das estradas de ferro, além de instrumento de trabalho nos engenhos e fazendas, alimento para a população, e provedor de subprodutos como o leite, o couro e a lâ. ${ }^{1}$

Sabe-se da imensidão das fazendas de criar no Piauí colonial que abastecia a Bahia e o Maranhão, e da criação sulina de muares que munia os mercados de Minas Gerais, Rio de Janeiro e São Paulo desde o tempo do ouro no século XVIII, até o do café no XIX. ${ }^{2}$ Surpreendentemente são pouco conhecidos os padrões de funcionamento dessas fazendas no que se refere à composição do rebanho, mão-de-obra utilizada, existência de produção agrícola, formas de financiamento e níveis técnicos de operação. No caso do Rio Grande do Sul ainda não conhecemos com precisão o volume, destino, distribuição espacial e evolução temporal do gado criado, em que pese ter sido o setor, ao lado das charqueadas, o centro da economia local. ${ }^{3}$ No caso do Paraná, a pecuária foi também a atividade mais rentável nos séculos XVIII e XIX, e sua importância já foi enfatizada por vários autores. Estudos importantes foram realizados por Brasil Pinheiro Machado, Altiva Pilatti Balhana e Cecília Maria Westphalen. ${ }^{4}$

Como em outros pontos do Brasil e da América espanhola, a pecuária no Paraná funcionou associando atividades correlatas: tropeirismo, 
invernagem e criação, e juntas conviveram, sobressaindo em períodos determinados alguma em particular. Na primeira metade do século XVIII, após a abertura da estrada do Sul por volta de 1733, a passagem crescente de tropas envolveu no comércio cada vez mais pessoas avizinhadas nos planaltos do Paraná. Os fazendeiros paranaenses participavam da venda de tropas indo buscar pessoalmente, ou mandando buscar, muares e cavalos sulinos. Esse comércio rapidamente incentivaria a formação de fazendas, seja para alugar pastos, seja para criar e vender animais, ou, com mais freqüência, ambas.

$\mathrm{O}$ aluguel de potreiros para os comboios de mulas vindas do Rio Grande do Sul em direção à feira de Sorocaba era um negócio atraente e incessante. $\mathrm{O}$ percurso era tão longo, e demorava tantos meses, que era necessário descansar as tropas e engordá-las várias vezes no trajeto antes de apresentá-las aos compradores, e os campos do Paraná eram um dos pousos principais. O negócio era lucrativo e fácil, isento de riscos, e acessível a todos que tivessem áreas de capim com aguadas e matas, características que nas pradarias dos planaltos abundavam. Na segunda metade do século XIX, sobretudo após 1870, foram as invernadas que acabaram ganhando o espaço da criação.

Mas na primeira metade do século XIX era a criação que estava no auge no Paraná. É este período que nos propomos analisar. Os fazendeiros do gado dominavam a economia local e eram os donos não apenas dos rebanhos, mas também da terra e dos escravos. Criavam principalmente vacuns e cavalares, e cultivavam alimentos para a subsistência, destacandose o milho. Empregavam ostensivamente o braço escravo, e bem menos o trabalho livre, incluído aí o familiar. Quem eram os fazendeiros? Qual o tamanho de suas fazendas? Quais os padrões de produção? É o que pretendemos discutir sucintamente fazendo uso de um recenseamento assaz completo disponível para as principais fazendas da região.

\section{Dados e representatividade}

Nos anos 1825-26 procedeu-se nas localidades do planalto paranaense ao arrolamento particularizado das fazendas de criar. Do cadastro constam dados como o nome da fazenda, nome do proprietário, número e tipos de 
animais existentes e número de escravos masculinos e femininos vinculados a cada produtor. Como nesses mesmos anos foram realizados também levantamentos gerais da população, é possível ampliar essas informações e conferir nas respectivas listas nominativas de habitantes a colheita de produtos agrícolas havida em cada unidade agropecuária, o número de agregados que nelas residiam, bem como as características demográficas dos fazendeiros e seus dependentes.

$\mathrm{O}$ arrolamento das fazendas abarcou todas as vilas e freguesias da área, com exceção da Lapa, porém, foi-nos dado aproveitar unicamente as informaçôes relativas a Castro e Ponta Grossa (freguesia subordinada a Castro). Nas demais localidades, infelizmente, o arrolamento não foi seletivo e contabilizou em algumas companhias de ordenanças não apenas as fazendas de criar, mas também domicílios cujos chefes caracterizavam-se tãosomente por possuir algum tipo de animal. Esta listagem exaustiva inutiliza o levantamento de zonas demograficamente importantes como Curitiba. ${ }^{5}$ No entanto, o engano dos recenseadores tem ao menos o mérito de alertar os historiadores para o fato de eventualmente ter existido um conceito mais ou menos definido sobre o que fosse uma fazenda de gado (e cujo sentido teria estado patente ou latente no caso dos recenseadores de Castro e Ponta Grossa), embora, pela documentação que compulsamos, não tivéssemos chegado a precisóes. O que resulta claro é que apenas o fato de possuir animais não era elemento suficiente para uma propriedade vir a ser considerada "fazenda". Tampouco o era o número de animais possuídos, variável que muda bastante: em Castro havia desde fazendas com rebanhos acima de 3.000 cabeças, até uma outra que não possuía nenhum animal próprio (dedicava-se apenas ao aluguel de pastos). Pela amostra de Castro, igualmente, é possível constatar que o número de escravos não definia uma fazenda; a presença de cativos mostra flutuações que vão de um na fazenda de Charco Grande a 69 em outra pertencente aos religiosos carmelitas. Talvez o fato de o dono lidar comercialmente com gado e sua propriedade estar vinculada à economia pastoril através da criação ou das invernadas, venha a ser um elemento-chave. Ficariam de lado os donos de animais que os possuíam apenas para uso próprio, independentemente do número de cabeças. Seja como for, um traço que foi comum a todas as propriedades identificadas como fazendas de gado em Castro e Ponta Grossa era o de 
receberem um nome próprio, detalhe que no levantamento de Curitiba não é uniforme.

Afortunadamente as informações de Castro e Ponta Grossa são exaustivas e, no geral, devem captar o padrão global das fazendas. Nesse ano a vila de Castro contava com 33 fazendas de criar e outras 12 localizavam-se em sua freguesia de Ponta Grossa. Em todas as fazendas, sem exceção, residiam escravos. Ao todo 762 cativos, dos quais quase a totalidade pertencente aos fazendeiros, salvo nove que viviam repartidos em duas fazendas de Castro na condição de agregados e mais dois que eram de propriedade de um capataz. Os fazendeiros alcançavam a 41 e dentre eles havia dois que possuíam três fazendas cada um. Comparando estes dados com aqueles disponíveis para a população escrava de 1824 , pode-se verificar que na localidade de Castro os donos de fazendas representavam por volta de $20 \%$ do conjunto dos proprietários de escravos e, por outro lado, nas suas propriedades viviam mais de 63\% do total de cativos da vila. Já em Ponta Grossa a presença dos fazendeiros revelou-se mais modesta face aos mesmos parâmetros: perfaziam quase $16 \%$ do total de escravistas e detinham cerca de $35 \%$ dos escravos da freguesia. ${ }^{6}$

Quanto aos animais é possível também avaliar de modo aproximado a magnitude relativa dos rebanhos de Castro e Ponta Grossa no contexto do Paraná. Para tanto, pode-se fazer uso do levantamento falho de Curitiba (que inclui as freguesias de São José dos Pinhais e Palmeira), no entendido que se trata de um indicador superestimado, pois ele incorporou além do gado dos fazendeiros, aquele que pertencia a outros indivíduos. Somando o número de animais do levantamento de Curitiba, Castro e Ponta Grossa se teria uma ordem de grandeza aceitável sobre as cabeças de gado que havia nas fazendas de gado do Paraná em 1825-26. A rigor, faltaria conhecer o rebanho da Lapa; sua ausência, porém, vê-se atenuada frente ao sobreregistro de gado em Curitiba e considerando que sua expressão demográfica não era, nesta época, muito significativa. Assim, o estoque total de vacuns sediados nas fazendas de gado do Paraná, com as ressalvas assinaladas, seria nesses anos de 52.610 cabeças, das quais cerca de 58\% estavam em Castro (42\%) e Ponta Grossa (16\%). Com relação ao gado cavalar, o total para o Paraná seria de 8.591 unidades, sendo 54\% vinculadas às fazendas de Castro (28\%) e Ponta Grossa (26\%). Outros tipos de animais comparecem na 
relação das fazendas com quantitativos mais modestos. Os muares alcançavam no Paraná a 367 cabeças, dos quais 140 (38\%) repartiam-se entre dois fazendeiros de Castro (em Ponta Grossa nenhum dono de fazenda relacionou muares). Finalmente, o total de carneiros e ovelhas no Paraná chegava a 3.165, dos quais $995(31 \%)$ pertenciam a donos de fazendas de Castro $(21 \%)$ e Ponta Grossa (10\%).

Em suma, o arrolamento de fazendas das duas localidades selecionadas, para as quais contamos com informação completa, parece ser suficientemente representativo do universo paranaense.

\section{Fazendas e fazendeiros}

Quem eram os fazendeiros do gado? Pela tradição colonial que reservava ao homem a chefia dos domicílios e o comando na subsistência do lar, era de se esperar que todas as fazendas fossem dirigidas por homens, salvo em caso de morte deste, quando seria a viúva que emergiria à cabeça da propriedade. Em Castro e Ponta Grossa foi o que efetivamente ocorreu, sem exceçôes à regra, mesmo nos casos de mulheres que herdaram propriedades, em cujo caso os recenseadores e as autoridades se reportaram ao marido. Oitenta por cento dos fazendeiros eram do sexo masculino e as sete fazendas que aparecem em poder de mulheres é por tratar-se de viúvas (ver tabela 1). Todos os fazendeiros eram brancos, casados (exceto um), e tinham todos, assim como as viúvas, acima de quarenta anos, sendo donos, a esta altura, além das fazendas e sítios, de uma biografia já quase completa de vida familiar, trabalho, viagens regionais, relações sociais e, no caso de alguns, de incursões em política, cargos públicos, corpo militar e hierarquia eclesiástica. Provinham, em geral, de antigas e abastadas famílias que se tinham tornado latifundiárias na primeira metade do século XVIII, requerendo sesmarias para si e os familiares e agregando aos lotes recebidos porções ainda maiores de terras incorporadas por posse ilegítima. A herança de patrimônios era, nesses fazendeiros, um traço marcante. Foram poucos os que no século XIX apareceram começando do nada, e quando os havia eram em geral portugueses, chegados seguramente com algum capital. Não constam, até onde foi possível averiguar, vaqueiros que tenham ascendido a fazendeiros após uma carreira profissional bem suce- 
dida. Além dos proprietários individuais figurou em 1825 como grande fazendeira, em Castro, a Ordem Terceira de Nossa Senhora do Carmo que detinha três fazendas e 98 escravos, constituindo o maior contingente particular de cativos do Paraná.

\section{Tabela 1 - Fazendeiros de gado em Castro e Ponta Grossa, 1825}

\begin{tabular}{|l|r|r|r|r|}
\hline Categoria & Castro & Ponta Grossa & Total & $\%$ \\
\hline Fazendeiros & & & & \\
\hline Homens & 22 & 11 & 33 & 80,5 \\
\hline Mulheres & 6 & 1 & 7 & 17,1 \\
\hline Religiosos Carmelitas & 1 & - & 1 & 2,4 \\
\hline Total & 29 & 12 & 41 & 100,0 \\
\hline No de fazendas & 33 & 12 & 45 & - \\
\hline
\end{tabular}

Das 33 fazendas de criar que havia em Castro, três eram de propriedade dos religiosos carmelitas e três de D. Onistarda Maria do Rosário. Assim, para o conjunto de 33 fazendas havia um total de 29 proprietários. Em Ponta Grossa, cada uma das 12 fazendas pertencia a proprietários diferentes.

Fonte: Arquivo do Estado de São Paulo, Listas Nominativas de Habitantes.

Se quase todos os fazendeiros eram brasileiros, em sua maioria também residiam na região, e não em partes distantes, poucos delegando o gerenciamento de suas propriedades a prepostos. Ao que parece, no século XVIII o absenteísmo foi maior ${ }^{7}$, mas deve ter decrescido conforme a pecuária ia ganhando importância econômica século adentro, e portanto justificando e motivando os donos a cuidarem de seus próprios negócios. O absenteísmo nas primeiras décadas do século XIX foi mínimo e, quando existente, explica-se porque se tratar de fazendeiros com várias fazendas e imóveis, escolhendo-se uma como residência e visitando-se as restantes periodicamente, sendo estas últimas administradas no dia-a-dia por capatazes. Três quartos dos fazendeiros residiam em suas próprias fazendas e outros vinte por cento em uma das várias possuídas. Apenas quatro pecuaristas em 1825 moravam longe da região e, mesmo assim, nem tanto, em São Paulo e Cotia (ver tabela 2). Nenhum residia em províncias distantes 
como Rio de Janeiro, Minas Gerais ou Rio Grande do Sul, ou ainda no Nordeste ou no exterior.

\section{Tabela 2 - Absenteísmo nas fazendas de gado de Castro e Ponta Grossa, 1825}

\begin{tabular}{|l|c|c|c|c|}
\hline Local de residência dos donos & Castro & Ponta Grossa & Total & $\%$ \\
\hline Reside na fazenda & 22 & 10 & 32 & 76,2 \\
\hline $\begin{array}{l}\text { Reside na vila, mas em } \\
\text { outra propriedade sua }\end{array}$ & 2 & - & 2 & 4,8 \\
\hline Reside em outra vila & 6 & 2 & 8 & 19,0 \\
\hline Castro & - & 1 & 1 & \\
\hline Palmeira & - & 1 & 1 & \\
\hline Curitiba & 1 & - & 1 & \\
\hline São Paulo & 3 & - & 3 & \\
\hline Cotia & 1 & - & 1 & \\
\hline Ignorada & 1 & - & 1 & \\
\hline Total & 30 & 12 & 42 & \\
\hline Não procede & 3 & - & 3 & 100,0 \\
\hline
\end{tabular}

a Trata-se das três fazendas dos religiosos carmelitas que eram administradas pelo capelão ou outros administradores.

Fonte: Arquivo do Estado de São Paulo, Listas Nominativas de Habitantes.

Qual era o tamanho das fazendas? Castro, que era o principal centro da pecuária nesta época, detinha também o maior número de fazendas e as com maiores extensões de terras. Os grandes latifúndios ficavam nesta região, e da superfície total de terras ocupadas no Paraná em 1818 segundo o Inventário de bens rústicos desse ano, 57\% dessas terras pertenciam a esta vila e suas freguesias. ${ }^{8}$ Os principais responsáveis pela apropriação das terras eram os fazendeiros do gado. Havia $18 \mathrm{com}$ propriedades entre 5.000 e 120.000 ha e em conjunto apossavam-se de mais de 610.000 ha que representavam 58\% da superfície ocupada de Castro e um terço da do Paraná. No entanto, a área média das fazendas de criar em Castro era de 22.179 ha 
(ver tabela 3). Em Ponta Grossa as fazendas tinham dimensões bem menores. Era uma freguesia nova que aumentou o número de fazendas (porém não o rebanho) nas décadas seguintes. ${ }^{9}$ Aqui a área média era de 7.026 ha e a maior propriedade pastoril tinha 21.780 ha. Ponta Grossa não apenas acolhia fazendas menores, como também em menor número (12 contra 33 em Castro), com menos escravos, menor número de cabeças e uma colheita agrícola interna mais acanhada. Mas não havia, assim como em Castro, fazendas minúsculas; a de menor tamanho, tanto em uma como na outra localidade, era de 545 ha. Dimensões demasiado pequenas seguramente teriam inviabilizado operações em escala comercial e a possibilidade de reunir, em um mesmo recinto, pecuária e lavoura de subsistência com os padróes de cultivo extensivos habituais.

\section{Tabela 3 - Área das fazendas de gado em Castro e Ponta Grossa em 1818}

\begin{tabular}{|c|c|r|r|r|r|r|c|}
\hline $\begin{array}{c}\text { Estratos } \\
\text { de área (ha) }\end{array}$ & $\begin{array}{c}\text { No de } \\
\text { fazendas }\end{array}$ & $\%$ & $\begin{array}{c}\text { Área total } \\
\text { (ha) }\end{array}$ & $\%$ & $\begin{array}{c}\text { Área média } \\
\text { (ha) }\end{array}$ & $\begin{array}{c}\text { Menor } \\
\text { fazenda } \\
\text { (ha) }\end{array}$ & $\begin{array}{c}\text { Maior } \\
\text { fazenda } \\
\text { (ha) }\end{array}$ \\
\hline 1. Castro & & & & & & & \\
\hline 500 a 999 & 1 & 3,4 & 545 & 0,1 & 545 & & \\
\hline 1000 a 4999 & 10 & 34,5 & 30.356 & 4,7 & 3.036 & & \\
\hline 5000 a 120000 & 18 & 62,1 & 612.290 & 95,2 & 34.016 & & \\
\hline Total & 29 & 100,0 & 643.190 & 100,0 & 22.179 & 545 & 117.612 \\
\hline 2. Ponta Grossa & & & & & & & \\
\hline 500 a 999 & 1 & 9,0 & 545 & 0,7 & 545 & & \\
\hline 1000 a 4999 & 5 & 45,5 & 7.623 & 9,9 & 1.525 & & \\
\hline 5000 a 22000 & 5 & 45,5 & 69.121 & 89,4 & 13.824 & & \\
\hline Total & 11 & 100,0 & 77.289 & 100,0 & 7.026 & 545 & 21.780 \\
\hline
\end{tabular}

As fazendas analisadas são as existentes em 1825 conforme relação das Listas Nominativas, mas a informação de área foi obtida no Inventário de 1818 por não constar das primeiras. Cinco fazendas, para as quais não foi possível averiguar sua área, foram excluídas. Fonte: Arquivo do Estado de São Paulo, Inventário dos Bens Rústicos de 1818 e Listas Nominativas de Habitantes de 1825. 
O rebanho relacionado pelos fazendeiros no levantamento de 1825 é modesto face ao que existia, por exemplo, no Rio Grande do Sul quarenta anos antes. O rebanho total de Castro era de 29.863 cabeças, incluindo gado vacum, cavalar, muar e lanígero. Somadas às 6.299 cabeças de Ponta Grossa resulta um total de 36.162 animais, o equivalente ao rebanho do distrito de Caí sulino e menor que o de Viamão. Mesmo acrescentando o estoque das demais localidades paranaenses, o total do Paraná seria, conforme nossas estimativas anteriormente comentadas, de 64.733 cabeças. Isto equivale a 7,3\% do total de 882.332 cabeças que havia no Rio Grande do Sul em $1787 .{ }^{10}$ Avançando no tempo as diferenças se agigantam. Só o município de Rio Grande e seus distritos, que em 1787 acolhia um quarto do rebanho gaúcho, em 1811 já contava com 1.298.379 cabeças, contabilizando apenas os vacuns, criados em 746 estâncias. ${ }^{11}$ A produção e o número de fazendas paranaenses tornava-se uma ninharia.

Mas no Paraná, para os padrões locais de propriedade e riqueza, e frente aos que nada tinham, esses modestos fazendeiros encarnavam modelos de opulência e fartura, eram os senhores do mundo e, claro, os donos dos meios de produção e de subsistência. Em termos de rebanhos sua preocupação central eram as vacas, os touros e os bois, ou seja, o gado vacum. Oitenta e quatro por cento do rebanho paranaense se compunha desta espécie. $\mathrm{O}$ cavalar vinha em segundo lugar e as ovelhas e carneiros em terceiro (tabela 4). As mulas e burros eram pouco criados, mas não por falta de vocação ou de incentivos econômicos, afinal, era o tipo de animal que mais se comercializava na feira de Sorocaba. ${ }^{12}$ Ocorre que sua criação legal fora confinada às regiôes ao sul do rio Iguaçu pelo governo de Morgado de Mateus (1765-1775), vigorando a medida até a primeira década do século XIX. Com essa providência pretendia-se criar estímulos econômicos para o assentamento estável de portugueses e brasileiros nas regiōes gaúchas, de modo a aplacar as pretensões espanholas na área. ${ }^{13} \mathrm{O}$ resultado foi a quase inexistência de muares nas fazendas paranaenses. Apenas dois fazendeiros de Castro investiram na espécie, encontrando o levantamento de 1825 magras 140 cabeças. 
Tabela 4 - 0 rebanho nas fazendas de gado de Castro e Ponta Grossa, 1825

\begin{tabular}{|l|r|r|r|r|}
\hline & \multicolumn{3}{|c|}{ Número de cabeças } & \\
\hline Tipo de rebanho & Castro & Ponta Grossa & Total & $\%$ \\
\hline Vacum & 25.592 & 4.795 & 30.387 & 84,0 \\
\hline Cavalar & 3.445 & 1.195 & 4.640 & 12,8 \\
\hline Muar & 140 & - & 140 & 0,4 \\
\hline Lanígero & 686 & 309 & 995 & 2,8 \\
\hline Rebanho total & 29.863 & 6.299 & 36.162 & 100,0 \\
\hline$\%$ & 82,6 & 17,4 & 100,0 & \\
\hline No de fazendeiros & 26 & 12 & 38 & \\
\hline Média de cabeças & 1.149 & 525 & 846 & \\
\hline
\end{tabular}

Nota: Foram excluídas três fazendas nas quais não foi possível conhecer o estoque de animas existentes. Ainda não foi computada uma outra fazenda que se dedicava unicamente a invernadas. O total de fazendas consideradas, então, foi de 41 que pertenciam a 38 fazendeiros.

Fonte: Arquivo do Estado de São Paulo, Listas Nominativas de Habitantes.

A distribuição do gado entre as fazendas era também diferente nas duas localidades analisadas. Em Castro a média por fazenda era de 1.030 cabeças e cerca da metade (525) em Ponta Grossa, considerando-se os quatro tipos de animais principais. Cinco por cento das fazendas criavam menos de 100 animais, $41 \%$ menos de 500, 68\% menos de 1000 , e $90 \%$ menos de 2000 cabeças. Mas a fazenda típica na primeira vila acolhia entre 1000 e 2000 animais, ao passo que na segunda ia de 100 a 500. Rebanho menor que 100 existia unicamente em duas fazendas de Castro, mas não havia nenhuma com menos de 60 cabeças. As grandes unidades pecuaristas, as de maior tamanho em estoque de cabeças, possuíam entre 2000 e 3500 animais, sempre com a proporção de vacuns dominando sem contrapeso na composição do rebanho, em torno dos $90 \%$ (tabela 5). Curioso é observar a omissão na relação de 1825 do gado suíno. A criação de porcos evidentemente existia e foi contabilizada em outros levantamentos $\operatorname{coevos}^{14}$, sendo sua criação tão abundante que se colocava em 1862 em terceiro lugar, atrás dos vacuns e cavalares, no número de cabeças. Os porcos, e 


\section{2 - Horacio Gutiérrez}

subprodutos como o toucinho, eram itens essenciais da dieta alimentar das fazendas e da população em geral, produzidos para autoconsumo, quando não também para comercialização.

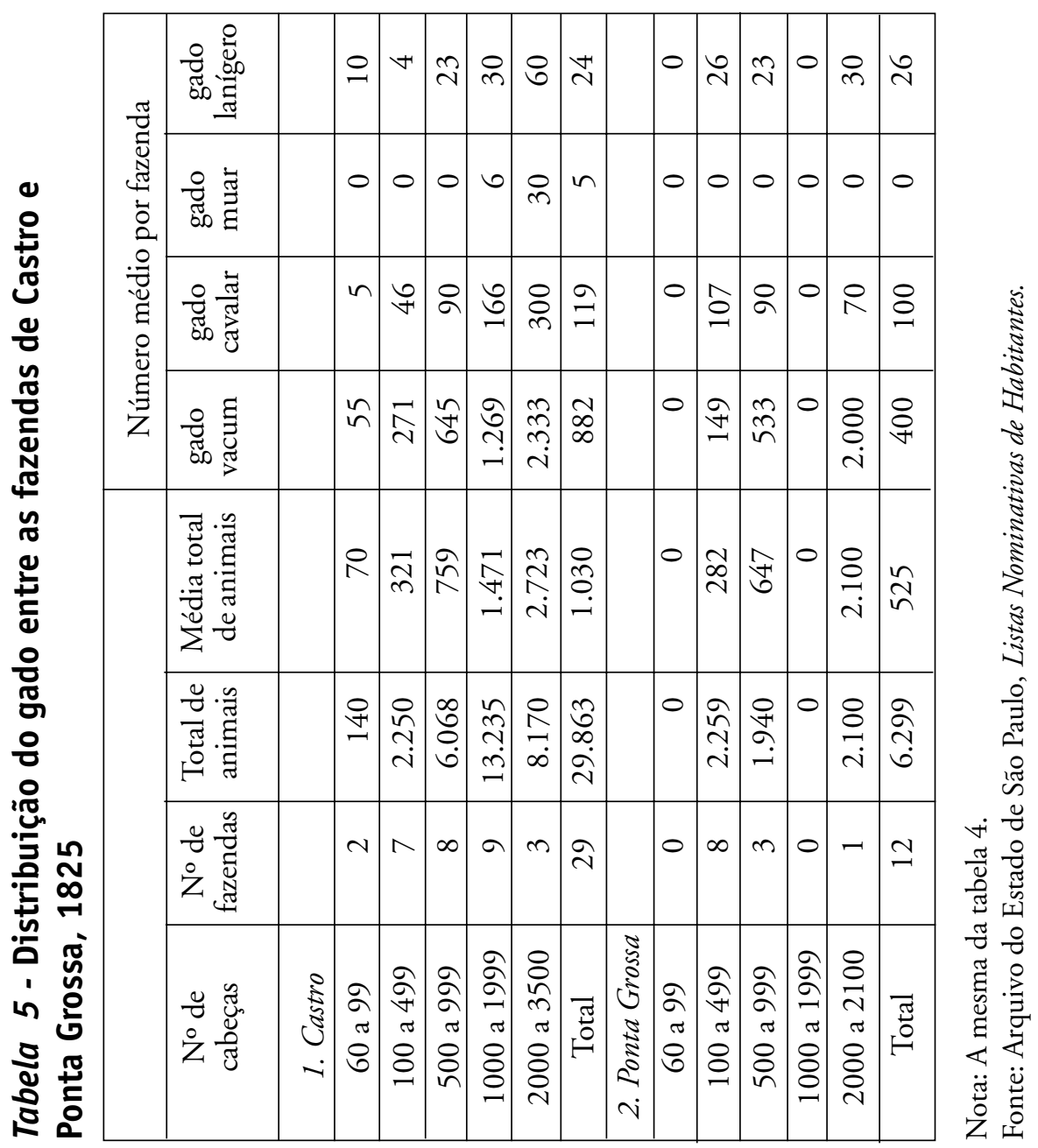


Além do gado, as fazendas cultivavam bens agrícolas de subsistência para a alimentação dos proprietários, agregados e escravos. Em lei de 1861, o presidente da província do Paraná definia como gêneros alimentícios de primeira necessidade o feijão, a farinha de mandioca e o milho, dentre os gêneros agrícolas, e o toucinho e o charque, dentre os oriundos da pecuária. Nos anos seguintes seria também incorporado à lista o arroz. ${ }^{15} \mathrm{Na}$ relação das fazendas de 1825 e nas listas nominativas respectivas figurou a colheita de três gêneros básicos: o milho, o feijão e o arroz. A mandioca não consta, mas deve ter sido plantada regularmente. Era um produto tão usual no litoral paranaense que não só o consumia, como o exportava para outras províncias na forma de farinha, e o planalto, no consumo, não ficava atrás. Em 1835, segundo Daniel Pedro Müller, Castro colheu 1.180 alqueires de mandioca. ${ }^{16} \mathrm{~A}$ quantidade era modesta porque seu objetivo era provavelmente apenas o abastecimento interno. Os três gêneros colhidos nas fazendas tinham aparentemente esse mesmo fim: o autoconsumo. A colheita total de milho foi em 1825 de menos de 6.000 alqueires nas fazendas de Castro e Ponta Grossa; a de feijão pouco mais de 1.000 e a de arroz de 165 alqueires (tabela 6). Mas a produção total dessas localidades (incluindo portanto todos os domicílios, e não apenas as fazendas) teria sido muito superior, a julgar pelos dados disponíveis para 1835. A colheita de milho foi nesse ano de 181.631 alqueires em Castro e sua freguesia, de 438.443 alqueires em Curitiba e 24.598 na Lapa. A de feijão de 6.691, 18.677 e 4.136 alqueires, respectivamente. E a colheita de arroz de 1.080, 480 , não havendo produção na Lapa. ${ }^{17}$ São ordens de grandeza que sugerem que a produção agrícola das fazendas era restrita, destinada antes para a própria alimentação, e menos para fins comerciais. 


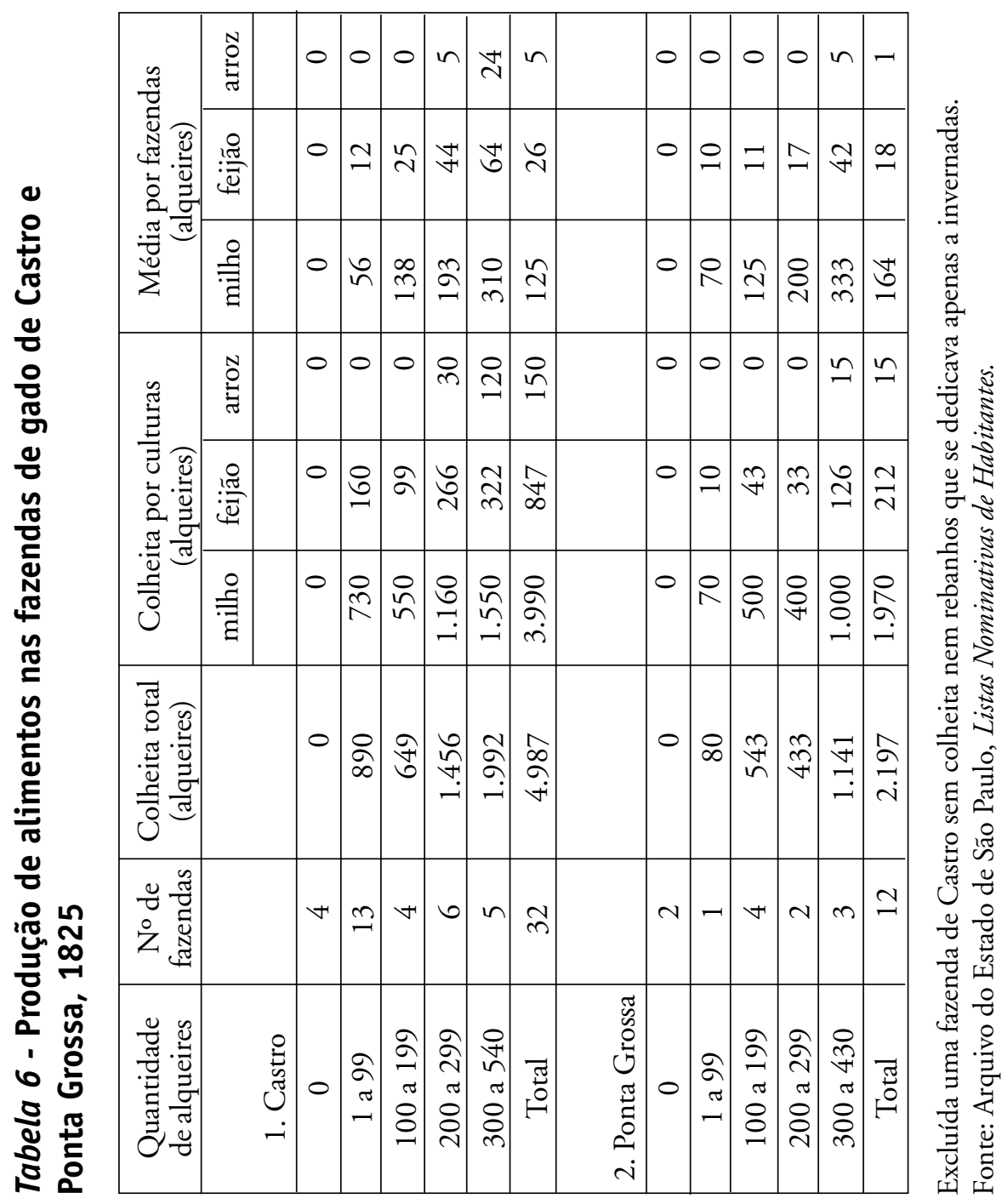

Por outro lado, das 44 fazendas analisadas, seis não relacionam produção agrícola. Compravam alimentos? $\mathrm{Na}$ verdade estas seis, em termos do número de trabalhadores a elas vinculados, estavam entre as de menor tamanho. Assim, seria de esperar que para elas fosse mais fácil plantar (precisariam menores áreas e sementes) e, ao mesmo tempo, mais difícil comprar 
(menos disponibilidade de renda). O mais provável é que a sua produção não tenha sido relacionada no levantamento de 1825 por seu significado pouco relevante, ou que a colheita neste ano se tenha perdido. Segundo SaintHilaire, todos os fazendeiros cultivavam a terra, não deixando de acrescentar que o faziam apenas "para suprir suas próprias necessidades". ${ }^{18}$

Quem trabalhava nas fazendas? Sem dúvida era importante o trabalho familiar do dono e o auxílio dos agregados, mas a mão-de-obra principal nas fazendas de criar do Paraná foi, pelo número e freqüência com que apareceu, a dos escravos. Não havia uma única fazenda que não contasse em 1825 com cativos, contudo, seus números variavam bastante: iam de um escravo na Fazenda do Charco Grande, até 69 no Capão Alto, dos frades carmelitas. Inclusive a Fazenda do Fundão, também dos carmelitas, que se dedicava exclusivamente a invernadas e não tinha gado próprio nem produção agrícola, era tocada por escravos, em número de sete. Já os agregados compareceram apenas em algumas fazendas, assim como a força de trabalho familiar, inexistente no caso dos fazendeiros absenteístas. Outros tipos de mãode-obra livre, como assalariados, meeiros, temporários etc., as fontes não os relacionam e devem ter sido residuais. Tampouco figuraram indígenas.

A distribuição dos escravos entre os fazendeiros revela uma posse média bem superior à vigente na população em geral. Em 1804 a média geral na propriedade de escravos no Paraná era de seis cativos, e vinte anos depois, de cinco. Em Castro em 1824 chegava a sete por proprietário e em Ponta Grossa a quatro. ${ }^{19}$ Entre os fazendeiros era de 22 na primeira vila e nove na segunda localidade (tabela 7). Eram os fazendeiros que monopolizavam os escravos, propriedade mais valiosa que a terra, e inclusive que o gado. Quase um terço dos donos de fazendas em Castro possuía entre um e nove cativos; outro terço entre 10 e 19 escravos, e o terço restante era conformado por fazendeiros que administravam expressivas posses para os padrões da região, de 20 ou mais cativos. Os fazendeiros desta última classe detinham $72 \%$ do total de escravos que vivia em fazendas de criação, mas o índice de Gini de 0,50 não acusa uma concentração extrema na posse de cativos. Em Ponta Grossa a distribuição era mais homogênea e o tamanho das posses também menor. Aqui, mais da metade dos proprietários de fazendas lidava com posses compostas por nove escravos ou menos e o fazendeiro mais abastado declarou-se dono de 25 cativos, contra 98 que possuía o principal fazendeiro de Castro. 


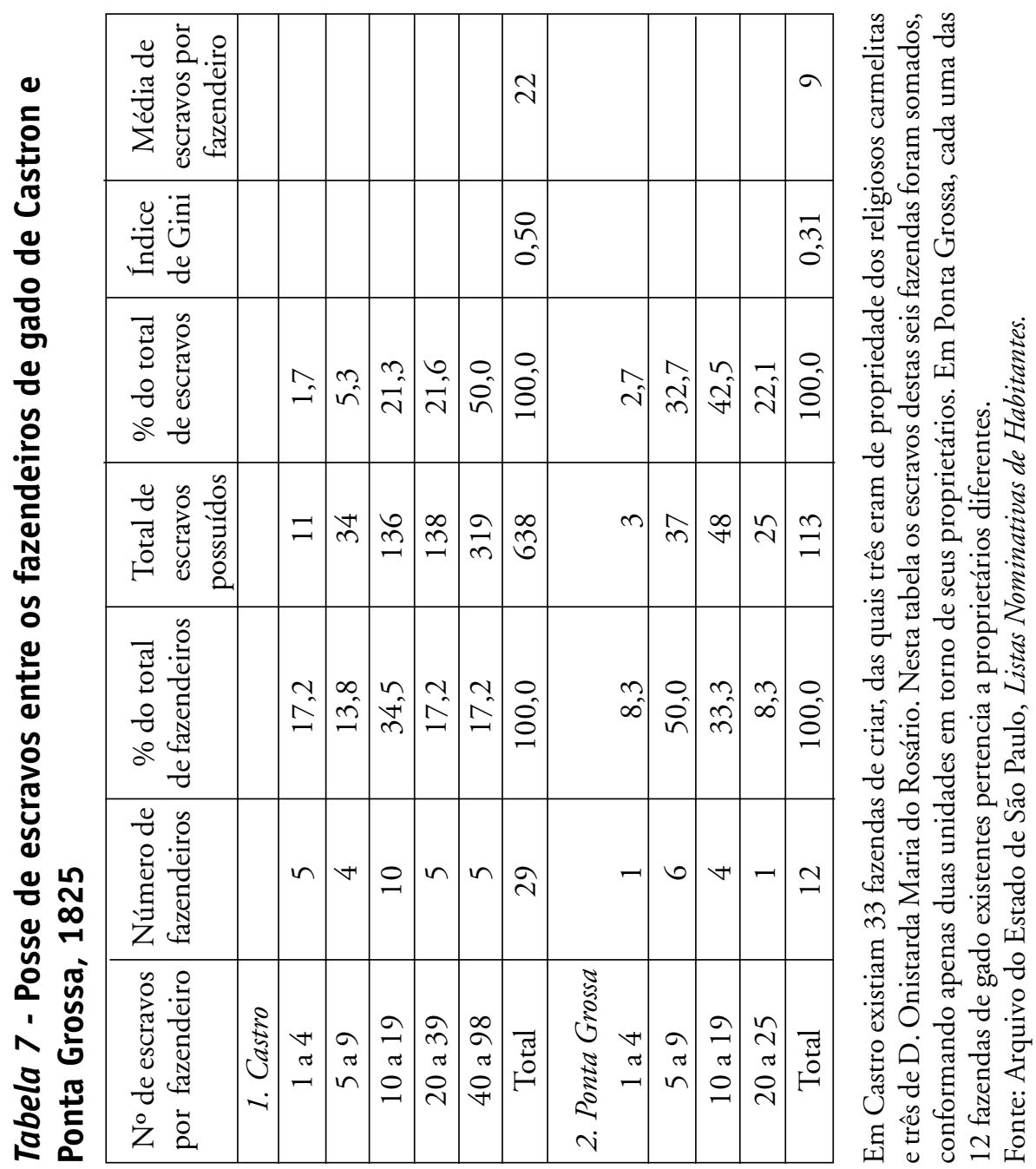

Não é possível saber com exatidão a tarefa específica que cumpriam os escravos no interior das fazendas, mas constaram alguns exercendo as funções de capataz ou condutor de tropas. Saint-Hilaire pôde observar escravos que participavam da marcação do gado, doma de potros chucros, castração de novilhos e do fornecimento de sal aos rebanhos que ocorria a cada dois ou quatro meses. Seguramente o trabalho mais rotineiro consis- 
tia em vigiar diariamente o gado e cuidá-lo de roubos, doenças, ferimentos, ataques de animais selvagens ou flechadas de índios, bem como participar de reparaçōes que fossem necessárias na fazenda e de tocar as plantações. A divisão sexual do trabalho reservava estas atividades basicamente aos homens. As mulheres, em contrapartida, deviam cuidar das tarefas domésticas, limpando e cozinhando, fazendo a farinha, os queijos e as velas, cuidando das crianças, das hortas e pomares caseiros, e da confecção de tecidos rústicos de lã ou algodão como cochonilhos, cobertores e roupas de trabalho. ${ }^{20}$ Quatro em cada dez escravos adultos nas fazendas eram mulheres, o que mostra um relativo equilíbrio entre os sexos, e as crianças com até nove anos de idade alcançavam a $20 \%$ do conjunto dos cativos. Era impressionante a proporção de crianças escravas na população cativa do Paraná, e no início do século XIX o contingente de menores foi ainda maior, de $27 \%$. O crescimento vegetativo positivo dos escravos foi, ao que parece, uma realidade na região, sendo a importação e compra de negros africanos pouco expressiva. ${ }^{21}$ Em Castro, em 1804, para cada escravo oriundo da África havia seis nascidos no Brasil. E entre os brasileiros, três quartos tinham nascido na própria vila, e os demais em outras localidades do Paraná, São Paulo ou Rio Grande do Sul que desembocavam na rota do muar. O que significa que a reposição da população escrava e seu aumento deve atribuir-se primordialmente a fatores internos. O papel das fazendas de gado, como detentoras de significativas posses, foi decisivo nesse processo.

A mão-de-obra das fazendas de criar não se compunha, contudo, apenas de escravos. Em menor medida, bem menor, eram tocadas também por trabalho familiar e por agregados. Em média, $72 \%$ da força de trabalho nas fazendas do Paraná era constituída de escravos, $17 \%$ por familiares do fazendeiro e $11 \%$ por agregados livres (ver tabela 8). Essa distribuição, uma média calculada com todos os estabelecimentos, variava no entanto com o tamanho da fazenda. Nas menores, com até nove escravos, o trabalho familiar e de agregados tinha um peso maior: os escravos representavam $56 \%$ da mão-de-obra utilizada, $31 \%$ o trabalho familiar e $13 \%$ os agregados. Nas fazendas que empregavam entre 10 e 39 cativos, a proporção de escravos crescia a $75 \%$, caindo para $15 \%$ o trabalho familiar e $10 \%$ os agregados. Era nas fazendas maiores, com mais de 40 cativos, onde proporcionalmente mais se utilizavam os escravos: seu peso subia a $86 \%$, di- 
minuindo o trabalho familiar a $6 \%$ e os agregados a $8 \%$. Ou seja, pode-se notar que o crescimento e consolidação de uma fazenda de criar significava a intensificação no uso de escravos e a diminuição relativa da força de trabalho familiar e livre. Apenas nas pequenas fazendas de gado o comparecimento da família e de trabalhadores agregados seria tão importante como a dos escravos, mas, conforme a fazenda se expandisse, as tarefas seriam gradativamente delegadas a cativos.

\section{Tabela 8 - Mão-de-obra nas fazendas de gado, Castro e Ponta Grossa, 1825}

\begin{tabular}{|c|c|c|c|c|c|}
\hline \multirow{2}{*}{$\begin{array}{c}\text { No de escravos } \\
\text { por fazenda }\end{array}$} & $\begin{array}{c}\text { No de } \\
\text { fazendas }\end{array}$ & Total de escravos & \multicolumn{3}{|c|}{ Número médio por fazenda } \\
\cline { 4 - 6 } & residentes & $\begin{array}{c}\text { livres } \\
\text { adultos }\end{array}$ & $\begin{array}{c}\text { escravos } \\
\text { adultos }\end{array}$ & $\begin{array}{c}\text { agregados } \\
\text { adultos }\end{array}$ \\
\hline 1 a 4 & 8 & 21 & 1 & 3 & 2 \\
\hline 5 a 9 & 11 & 78 & 4 & 6 & 0 \\
\hline 10 a 19 & 13 & 167 & 3 & 10 & 1 \\
\hline 20 a 39 & 8 & 208 & 3 & 20 & 3 \\
\hline 40 a 69 & 5 & 288 & 3 & 45 & 4 \\
\hline Total & 45 & 762 & 3 & 13 & 2 \\
\hline
\end{tabular}

Obs.: a) A coluna dos livres refere-se ao fazendeiro e sua família (esposa, filhos e demais parentes presentes na fazenda). Nas colunas dos escravos foram computados, além dos escravos de propriedade dos fazendeiros, nove que residiam em fazendas a título de "escravos agregados" (ocorrência verificada em duas fazendas), e dois que pertenciam a um capataz (ocorrência encontrada em outra fazenda). Por outro lado, a coluna dos agregados registra exclusivamente agregados livres. b) Consideraram-se adultas as pessoas com 10 ou mais anos.

Fonte: Arquivo do Estado de São Paulo, Listas Nominativas de Habitantes.

\section{Os fazendeiros endinheirados}

Quem eram os grandes fazendeiros? Há vários critérios possíveis para identificá-los e hierarquizá-los. A primazia estava na superfície de terra que detinham? No número de escravos empregados? No número de cabeças de gado possuídas? Não havia uma correlação perfeita entre essas variáveis. 
Assim, optamos por classificá-los de acordo com as variáveis área e número de escravos, tendo em vista que o número de cabeças era mais elástico. Além disso, unificamos, na quantificação, os dados das fazendas que pertenciam a um mesmo proprietário.

Os mais importantes e ricos fazendeiros tinham todos propriedades em Castro, e entre os dez principais apenas um era de Ponta Grossa, quando consideramos o critério dos escravos possuídos (tabela 9). A fazendeira mais opulenta e famosa em 1825 era Dona Onistarda Maria do Rosário, viúva do tenente-coronel José Félix da Silva, fiel vassalo de Sua Majestade, que em vida foi dono de quatro fazendas, três delas em Castro, todas gigantescas, mas passou à História antes pela lenda que envolveu sua vida e sua relação tumultuada com a mulher. A história é tão rocambolesca que deu origem a um romance, O Drama da Fazenda Fortaleza, do gênero crime passional com suspense. ${ }^{22}$ Segundo o autor, o romancista e também historiador Davi Carneiro, foi a esposa que envenenou o marido em 1822, data de seu desenlace, depois de duas tentativas fracassadas de assassiná-lo. José Félix, português de origem, havia conhecido e se apaixonado por Onistarda em Santos. Tempo depois se casam em Curitiba e seguem para a Fazenda Fortaleza, descobrindo o marido, na noite de núpcias, que sua mulher não era virgem. Instalou-se uma relação de ódio e mútuo desprezo. Ele decidiu não deixá-la ir embora, enclausurando-a dentro de casa. Nasce a filha Ana Luzia, a única do casal, mas José Félix desconfia não ser o pai. Após anos de vida infernal, na segunda tentativa de assassinato, numa emboscada com mascarados, o coronel, sempre valente, conseguiu revidar e descobriu-se que o mandante havia sido sua mulher. A Justiça condena D. Onistarda à prisão, mas Félix solicita e consegue que a pena seja cumprida na própria Fazenda Fortaleza. A partir de então ela passaria a viver encarcerada em sua própria casa. 
$120 \cdot$ Horacio GutiérRez

Tabela 9 - 0s 10 maiores fazendeiros de gado de Castro e Ponta Grossa, 1825

\begin{tabular}{|c|c|c|c|c|c|c|c|c|c|c|c|c|c|}
\hline 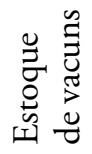 & & 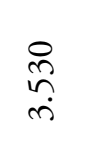 & ণ & $\begin{array}{l}8 \\
\varnothing \\
\varnothing \\
\dot{0}\end{array}$ & $\begin{array}{l}\stackrel{0}{\sim} \\
\sim\end{array}$ & 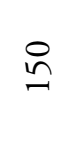 & $\begin{array}{l}8 \\
8 \\
\bigcirc \\
\text { نे }\end{array}$ & $\underset{\stackrel{ }{\sim}}{\stackrel{ }{\sim}}$ & 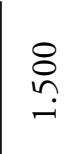 & 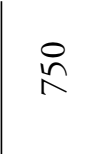 & ஓ & $\begin{array}{l}\stackrel{8}{尺} \\
\stackrel{1}{n}\end{array}$ & 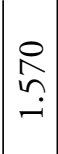 \\
\hline 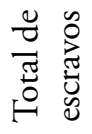 & & $\widehat{\sigma}$ & 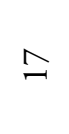 & $\stackrel{g}{\forall}$ & $\hat{n}$ & $\underset{\sim}{\sim}$ & 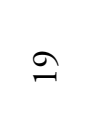 & $\stackrel{\infty}{\curvearrowleft}$ & $\stackrel{\sim}{\sim}$ & $\stackrel{\sim}{\sim}$ & 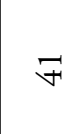 & 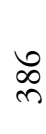 & $\tilde{m}$ \\
\hline 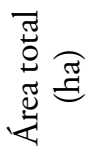 & & $\begin{array}{l}\stackrel{0}{0} \\
+\longleftarrow \\
\text { Ṅ } \\
\end{array}$ & 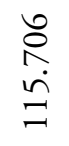 & 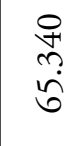 & $\begin{array}{l}\stackrel{+}{~} \\
\text { ஸे }\end{array}$ & $\begin{array}{l}\stackrel{+}{~} \\
\text { ஸे } \\
\text { กे }\end{array}$ & $\begin{array}{l}\stackrel{0}{\Omega} \\
\text { กิ } \\
\text { n் }\end{array}$ & 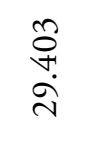 & 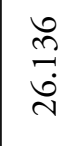 & 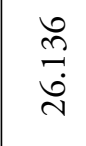 & 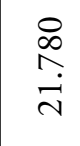 & 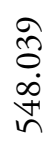 & 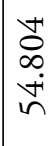 \\
\hline 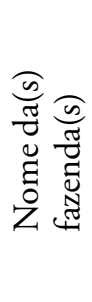 & & 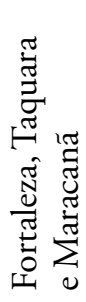 & $\frac{\stackrel{\circ}{\Xi}}{\stackrel{\overbrace \Xi}{\Xi}}$ & 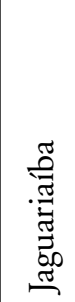 & $\begin{array}{l}. \stackrel{0}{\Xi} \\
\stackrel{\Xi}{\Xi} \\
. \Xi\end{array}$ & $\begin{array}{l}\stackrel{\tilde{\pi}}{\pi} \\
\frac{\mathcal{Z}}{Z}\end{array}$ & 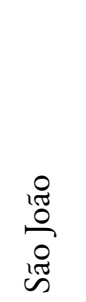 & 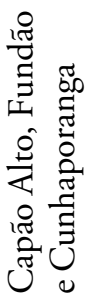 & 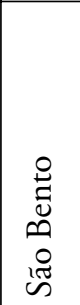 & 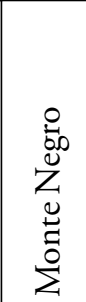 & 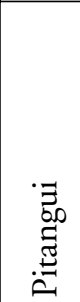 & & \\
\hline 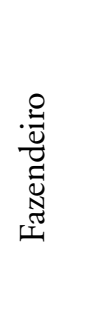 & $\begin{array}{l}3 \\
8 \\
8 \\
8 \\
8 \\
8 \\
8 \\
8 \\
8 \\
0 \\
8 \\
8\end{array}$ & 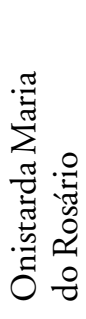 & 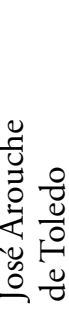 & 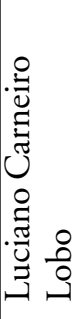 & 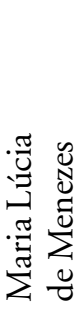 & 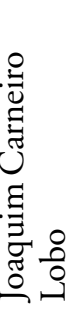 & 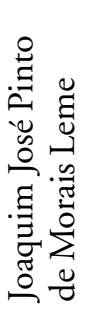 & 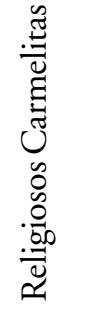 & 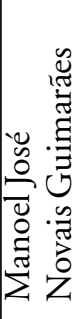 & 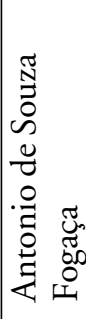 & 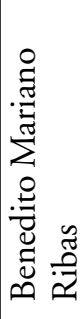 & & \\
\hline $\begin{array}{l}\frac{\tilde{v}}{\tilde{\tau}} \\
\frac{.0}{\tilde{J}} \\
0 \\
.\end{array}$ & 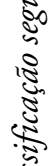 & 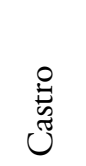 & 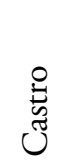 & 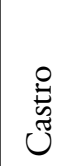 & 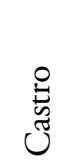 & 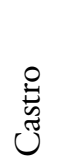 & 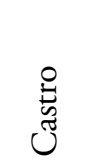 & 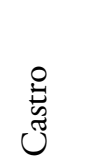 & 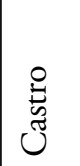 & 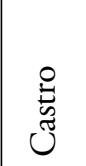 & 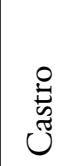 & & \\
\hline$\stackrel{\circ}{Z}$ & $\vec{v}$ & - & $N$ & $m$ & $\checkmark$ & $n$ & 6 & $\Lambda$ & $\infty$ & $a$ & $\stackrel{0}{ }$ & 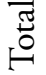 & $\sum_{2}^{0}$ \\
\hline
\end{tabular}




\begin{tabular}{|c|c|c|c|c|c|c|c|c|c|c|c|c|}
\hline & 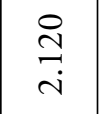 & 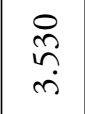 & 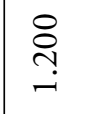 & $\begin{array}{l}\stackrel{8}{0} \\
\dot{n}\end{array}$ & $\underset{\overbrace{}}{\stackrel{\overbrace{}}{~}}$ & 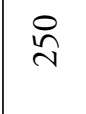 & $\underset{\text { ㄱ. }}{\stackrel{\text { }}{N}}$ & ৪ & $\begin{array}{l}8 \\
\stackrel{8}{2} \\
\stackrel{1}{-}\end{array}$ & $\stackrel{\circ}{n}$ & $\begin{array}{l}\stackrel{2}{1} \\
\infty \\
i \\
\end{array}$ & $\begin{array}{l}\hat{\infty} \\
\stackrel{\sim}{\sim} \\
-\end{array}$ \\
\hline & $\stackrel{\infty}{\curvearrowleft}$ & $\widehat{\sigma}$ & ث্ & $\stackrel{+}{+}$ & F & $\hat{n}$ & $\stackrel{m}{n}$ & $\approx$ & $\stackrel{\sim}{\sim}$ & $\ddot{\sim}$ & $\vec{b}$ & $\stackrel{\odot}{\forall}$ \\
\hline & $\begin{array}{l}\text { oे } \\
\text { †े } \\
\text { خे }\end{array}$ & 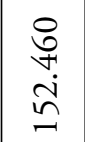 & $\begin{array}{l}\infty \\
\stackrel{\infty}{i}\end{array}$ & 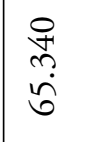 & $\begin{array}{l}\infty \\
\stackrel{\infty}{\stackrel{\sim}{\lambda}}\end{array}$ & $\begin{array}{l}\stackrel{+}{ } \\
\stackrel{n}{*} \\
\grave{m}\end{array}$ & $\begin{array}{l}\hat{\approx} \\
\tilde{n} \\
\hat{n}\end{array}$ & $\stackrel{\text { ळे }}{\stackrel{-}{-}}$ & $\begin{array}{l}0 \\
\stackrel{\sim}{*} \\
\stackrel{\sim}{*}\end{array}$ & $\begin{array}{l}0 \\
\stackrel{n}{*} \\
\dot{d}\end{array}$ & $\begin{array}{l}\sqrt{0} \\
\stackrel{1}{0} \\
\stackrel{n}{n}\end{array}$ & $\begin{array}{l}\hat{N} \\
\hat{\delta} \\
\stackrel{n}{n}\end{array}$ \\
\hline & 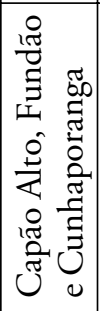 & 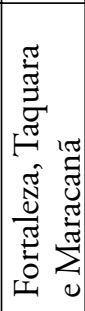 & 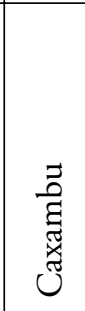 & 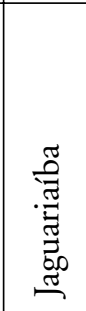 & $\begin{array}{l}\overrightarrow{\vec{E}_{0}} \\
\stackrel{\vec{E}}{\vec{E}}\end{array}$ & 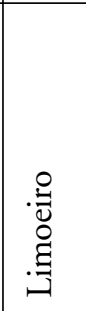 & $\frac{\ddot{\circ}}{\stackrel{0}{\pi}}$ & 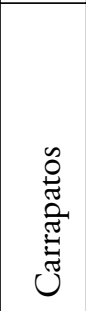 & 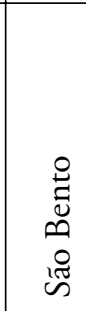 & 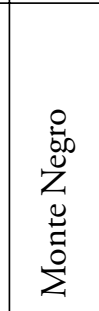 & & \multirow[b]{4}{*}{$\mathbb{0}$} \\
\hline \multirow{3}{*}{ 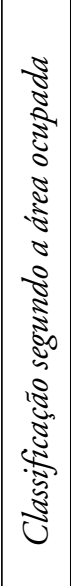 } & 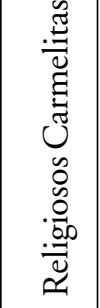 & 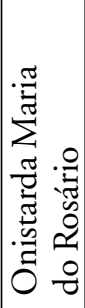 & 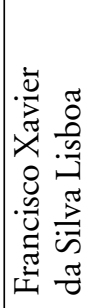 & 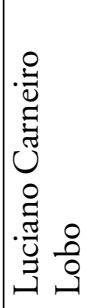 & 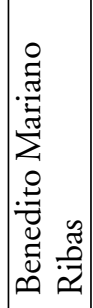 & 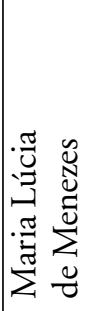 & 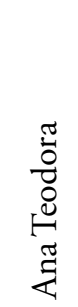 & 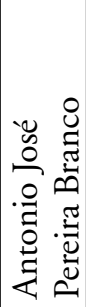 & 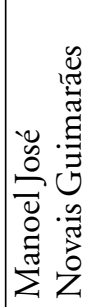 & 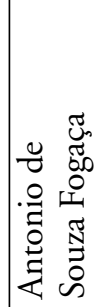 & & \\
\hline & 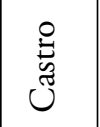 & 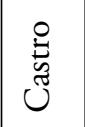 & 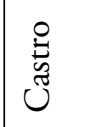 & 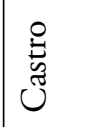 & 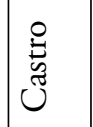 & $\underset{\stackrel{\Xi}{\tilde{J}}}{\stackrel{O}{J}}$ & 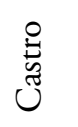 & 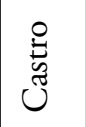 & 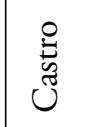 & 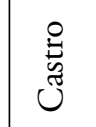 & & \\
\hline & - & $\sim$ & $n$ & 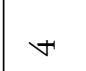 & $n$ & 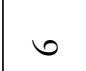 & $\Lambda$ & $\infty$ & $a$ & $\stackrel{ }{ }$ & \begin{tabular}{|c|}
$\pi$ \\
0 \\
0
\end{tabular} & \\
\hline
\end{tabular}


Quanto há de ficção nessa história e quanto de realidade continua sendo um mistério, embora Davi Carneiro assegure que as personagens, sua psicologia e o enredo que constam em seu romance sejam todos verdadeiros. ${ }^{23} \mathrm{E}$ o perspicaz Auguste de Saint-Hilaire, que conheceu o casal durante sua visita à Fortaleza em 1820, confirma muitos dos fatos. $\mathrm{O}$ viajante achou José Félix um dos mais ricos proprietários da província de São Paulo, e mencionou sua notável avareza. ${ }^{24} \mathrm{Na}$ relação das sesmarias concedidas no século XVIII consta ele recebendo uma em 1788, de 13.068 ha, nos Campos Gerais. Suas propriedades, no entanto, tinham em 1818 superfícies bem maiores: a Fazenda Fortaleza era a maior unidade pastoril de Castro e Ponta Grossa, com 117.612 ha de terras, e perdia por pouco em extensão para a maior propriedade rural do Paraná desse ano. A segunda, Taquara, ascendia a 6.136 ha, e a menor, Maracanã, tinha 8.712. Em número de escravos, D. Onistarda aparece em 1825 com fortuna também incomensurável: era a segunda escravista do Paraná com 67 cativos distribuídos em suas três propriedades de Castro, além de possuir 3.530 cabeças de gado vacum, 1.090 eqüinos e extensas plantações de milho, feijão, arroz e algodão.

Em número de escravos, D. Onistarda era superada apenas pela Ordem Terceira de Nossa Senhora do Carmo, sediada no convento da Ordem em São Paulo. Os carmelitas tinham também três fazendas em Castro dedicadas à pecuária: Capão Alto com 16.335 ha, Fundão com 9.801 e Cunhaporanga com 3.267 ha. As terras da primeira tinham sido adquiridas pelos frades, em 1751, do principal pecuarista da época, o capitão José de Góes e Morais. A extensão das três não era das maiores do planalto, mas sim o número de escravos, 98, que se repartiam basicamente entre a primeira e a última fazenda, pois a do Fundão era dedicada apenas a invernar tropas em trânsito que se dirigiam a Sorocaba, oriundas do Rio Grande do Sul. Em 1825 ela era a única fazenda em Castro e Ponta Grossa reservada a este uso exclusivo, que foi se ampliando na segunda metade do século XIX e principalmente após 1870, quando a criação no Paraná perdeu em importância e rentabilidade para o aluguel de pastos e a engorda do gado sulino. Os carmelitas tinham fazendas, imóveis e propriedades em toda a província de São Paulo, em números fantásticos. Na cidade de São Paulo, onde estavam instalados desde 1597, tinham em 1835, segundo Daniel 
Pedro Müller, 31 casas de aluguel, seis estabelecimentos de agricultura, uma fazenda de criar e 130 e tantos escravos, "de onde provém o seu rendimento". Em Mogi das Cruzes, três casas de morada, cinco estabelecimentos de agricultura e 80 escravos; em Santos, 18 moradas de casas, quatro fazendas, terrenos que aforavam, e 140 escravos para rendimento, e assim por diante. $^{25}$

José Arouche de Toledo, o terceiro proprietário em importância pelo critério da área apropriada, era dono da fazenda Curralinho, mas não residia nela. Morava em São Paulo, e de idade beirava os 70 anos. Ficamos na dúvida se se trataria do conhecido José Arouche de Toledo Rendon, de ilustre e abonada família, autor de uma monografia sobre os aldeamentos indígenas. Ao que parece, trata-se dele mesmo. Não encontramos em nossas buscas um homônimo em São Paulo da época com esse nome, nem com riqueza e faixa etária suficiente para ser titular de uma fazenda. Rendon tinha sete irmãs solteiras conhecidas como as "mocinhas da Casa Verde", proprietárias de uma fazenda com esse nome, onde ele se dedicou a plantar café. Em 1818, no Inventário dos Bens Rústicos, figura como proprietária da Curralinho D. Caetana Antonia de Toledo Correa Franca, ao que tudo indica, uma das "mocinhas" (tinha uma irmã denominada Caetana de Toledo). De profissão advogado, formado em Coimbra, Rendon cultivou, como a elite imperial, uma vida pública intensa e versátil: entre outras coisas, foi procurador da Coroa e da Fazenda Real; diretor geral dos índios; juiz de órfãos; governador de armas de São Paulo; diretor da Academia de Ciências Sociais e Jurídicas de São Paulo; e deputado eleito à Assembléia Constituinte brasileira de 1823. Como militar chegou a tenentegeneral. Como fazendeiro introduziu na província a cultura e o fabrico do chá, e foi um dos primeiros a exportar café. ${ }^{26}$ Mas, no Paraná, como fazendeiro de gado, passou despercebido.

Entre as outras grandes fazendas visitadas por Saint-Hilaire em sua viagem de 1820 está a de Jaguariaíba, do coronel Luciano Carneiro Lobo, e a Caxambu, de Francisco Xavier da Silva Lisboa. A fazenda do coronel, por ele fundada, ficava nas proximidades do rio do mesmo nome, cercada por bosques de araucárias e campos de pastagens, longe de centros urbanos e bem perto dos índios coroados, com os quais vivia em contendas. Grande admirador de Sua Alteza, tinha bom trânsito político local e mui- 
to prestígio entre os criadores. Havia nascido no Capão Alto, distrito de Curitiba, em 1761, e se casou e morou sempre na região. ${ }^{27}$ Tinha o perfil típico do grande fazendeiro paranaense da época - natural da terra, próspero, bem relacionado, frugal e administrando pessoalmente seus negócios. Sua casa era modestíssima.

Bem diferente era a residência de Francisco Xavier da Silva Lisboa, da fazenda Caxambu, uma morada esplêndida. Saint-Hilaire achou-a encantadora, situada na encosta de um morro, recortada por um riacho, com jardins verdejantes, demarcados por roseiras, todas enfileiradas, contrastando, na cor, ao fundo, com folhas escuras de limoeiros, e laranjeiras, figueiras e variadas árvores frutíferas selecionadas, devidamente alinhadas, cercadas de muros, artisticamente construídos, além da horta, junto da casa, também cercada, com canteiros bem tratados, e couves simetricamente plantadas. ${ }^{28}$ Mas Francisco Xavier era um homem incomum, e especial, o único solteiro entre os fazendeiros de gado, disciplinado e rigoroso, e célebre por sua bondade extrema. Português de nascimento, seu perfil fugia dos moldes locais.

A resenha de algumas biografias notáveis mostram a integrantes da elite que dominou o Paraná escravista em sua fase de esplendor. O ciclo do gado havia gerado uma economia, uma cultura e modos de vida que permaneceriam gravados na geografia e na história da região. A pecuária, junto ao latifúndio e aos escravos negros, marcaria uma época do desenvolvimento local sem parâmetros anteriores de comparação. A segunda metade do século XIX assinalaria o fim desta estrutura tradicional e o nascimento gradual de outra, caracterizada pela presença do trabalhador livre e assalariado, a entrada de migrantes estrangeiros e nacionais, a disseminação da pequena propriedade, o advento da ferrovia, a emergência de novos produtos agrícolas dominantes, como o mate, e a expansão da economia urbana. A pecuária permaneceria como setor produtivo, mas destituída da grandeza de outrora, sem escravos, e com fazendeiros privados de supremos poderes. 


\section{Notas}

${ }^{1} \mathrm{O}$ papel da pecuária como componente central no fomento do comércio inter-regional é demonstrado por Maria Thereza Schorer Petrone, O Barão de Iguape, São Paulo: Companhia Editora Nacional, 1976. Ver também da mesma autora, As áreas de criação de gado. Em: Sérgio Buarque de Holanda (org.). História Geral da Civilização Brasileira, 4a ed., Rio de Janeiro: Difel, v. 2, pp. 218-227, 1977.

${ }^{2}$ Sobre o Piauí existem dois trabalhos pioneiros: Luiz Mott, Piauí colonial: população, economia, sociedade, Teresina: Projeto Petrônio Portella, 1985, e Miridan Britto Knox Falci, Escravos do sertão: demografia, trabalho e relaçôes sociais. Piauí, 1826-1888. Teresina: Fundação Cultural Monsenhor Chaves, 1995. A questão do abastecimento no Centro-Sul é tratada por Mafalda P. Zemella, O abastecimento da Capitania das Minas Gerais no século XVIII. São Paulo: Hucitec/Edusp, 1990; e Alcir Lenharo, As tropas da moderação: o abastecimento da Corte na formação política do Brasil, 1808-1842. São Paulo: Símbolo, 1979.

${ }^{3}$ A pecuária é analisada no trabalho de Helen Osório, Estancieiros, lavradores e comerciantes na constituição da estremadura portuguesa na América, tese de doutorado, UFF, 1999. A charqueada recebe atenção no livro de Mário José Maestri Filho, O escravo no Rio Grande do Sul: a charqueada e a gênese do escravismo gaúcho, Porto Alegre: EST/Educs, 1984; no mais antigo de Fernando Henrique Cardoso, Capitalismo e escravidão no Brasil meridional, Rio de Janeiro: Paz e Terra, 1977; e no mais recente de Stephen Bell, Campanha Gaúcha: A Brazilian Ranching Sustem, 1850-1920, Stanford: Stanford University Press, 1998. Caio Prado Júnior contextualiza a pecuária gaúcha dentro dos mercados internos em História econômica do Brasil, São Paulo: Brasiliense, 1977, pp. 94-100.

${ }^{4}$ Brasil Pinheiro Machado, Contribuição ao estudo da história agrária do Paraná. I: Formação da estrutura agrária tradicional dos Campos Gerais, Anais do II Simpósio Nacional dos Professores Universitários de História, 1962, p. 129-155; Altiva Pilatti Balhana \& Cecília Maria Westphalen, Fazendas do Paraná provincial, Anais do VIII Simpósio Nacional dos Professores Universitários de História, v. 2, 1976, pp. 391-406.

${ }^{5} \mathrm{O}$ levantamento de Curitiba foi realizado em 1826 e contabilizou 258 fazendas na vila (incluindo no cômputo as freguesias de São José dos Pinhais e Palmeira). Este número é a todas as luzes inverossímil frente a outros levantamentos contemporâneos: um arrolamento feito em 1772 registrou a existência de 29 fazendas na área dos Campos Gerais; em 1836 o número de fazendas de criar no Paraná havia aumentado para 88 segundo Daniel Pedro Müller, sendo que 38 localizavam-se em Curitiba e suas freguesias. E ainda em 1862 o total de fazendas de gado chegava no Paraná a apenas 233, levando-se em conta as existentes em Curitiba, Lapa, Ponta Grossa, Palmeira, Palmas, Guarapuava e Rio Negro (só não há dados para São José dos Pinhais). No que se refere a Castro e Ponta Grossa, o levantamento de 1825 enumera 45 fazendas para estas localidades, número que se harmoniza com os demais arrolamentos e com a curva ascendente que registra a pecuária no Paraná até a década de 1860. Cf. Brasil Pinheiro Machado, op.cit., p. 136; Daniel Pedro Müller, Ensaio d'um quadro estatístico da Província de São Paulo (1837), São Paulo: Go- 
verno do Estado de São Paulo, 1978, p. 131; Altiva Pilatti Balhana \& Cecília Maria Westphalen, op.cit., p. 395.

${ }^{6}$ Horacio Gutiérrez, Senhores e escravos no Paraná, 1800-1830. Dissertação de mestrado em Economia, Universidade de São Paulo, mimeo, 1986.

${ }^{7}$ Marina Lourdes Ritter, As sesmarias do Paraná no século XVIII, Curitiba: Instituto Histórico, Geográfico e Etnográfico Parananense, 1980, p. 180.

${ }^{8}$ Horacio Gutiérrez, "A estrutura fundiária no Paraná antes da imigração". Estudos de História, Franca, v. 8, n. 2, 2001, pp. 209-231.

${ }^{9}$ Altiva Pilatti Balhana \& Cecília Maria Westphalen, op. cit., p. 395.

${ }^{10}$ Corcino Medeiros dos Santos, Economia e sociedade do Rio Grande do Sul, século XVIII, São Paulo: Companhia Editora Nacional, 1984, p. 82.

${ }^{11}$ Corcino Medeiros dos Santos, op. cit., p. 85.

${ }^{12}$ Aluísio de Almeida, Vida e morte do tropeiro, São Paulo: Martins/ Edusp, 1981; Herbert S. Klein, "A oferta de muares no Brasil Central: o mercado de Sorocaba, 1825-1880", Estudos Econômicos, v. 19, n. 2, 1989, pp. 347-372.

${ }^{13}$ Maria Thereza Schorer Petrone, O Barão de Iguape. São Paulo: Companhia Editora Nacional, 1976, pp. 18 e 39.

${ }^{14}$ Daniel Pedro Müller, op.cit., p. 128; Altiva Pilatti Balhana \& Cecília Maria Westphalen, op. cit., pp. 396 e 400.

${ }^{15}$ Citado por Carlos Roberto Antunes dos Santos, História da alimentação no Paraná, Curitiba: Fundação Cultural, 1995, p. 133.

${ }^{16}$ Daniel Pedro Müller, op. cit., p. 128.

${ }^{17}$ Daniel Pedro Müller, op. cit., p. 128.

${ }^{18}$ Auguste de Saint-Hilaire, Viagem a Curitiba e Província de Santa Catarina (1820). São Paulo: Edusp, 1978, p. 23.

${ }^{19}$ Horacio Gutiérrez, Senhores e escravos no Paraná, 1800-1830. Dissertação de mestrado em Economia, Universidade de São Paulo, mimeo, 1986, p. 44.

${ }^{20}$ Auguste de Saint-Hilaire, op. cit., pp. 42-44.

${ }^{21}$ Horacio Gutiérrez, "Demografia escrava numa economia não-exportadora: Paraná, 18001830". Estudos Econômicos, v. 17, n. 2, 1987, pp. 310-311, e "Crioulos e africanos no Paraná, 1798-1830”. Revista Brasileira de História, v. 8, n. 16, 1988, pp. 167-74.

${ }^{22}$ Davi Carneiro, O drama da fazenda Fortaleza. Curitiba: Dicesar Plaisant, 1941.

${ }^{23}$ Detalhes do episódio e sua construção histórica em Pedro do Rosário Neto, "O jogo das representações em torno do drama da fazenda Fortaleza”, História: Questôes e Debates, n. 20-21, 1990, pp. 103-121; Oney Barbosa Borba, "Seqüelas do atentado contra a vida do coronel José Félix da Silva Passos”, Boletim do Instituto Histórico, Geográfico e Etnográfico Paranaense, v. 49, 1995, pp. 223-262.

${ }^{24}$ Auguste de Saint-Hilaire, op. cit., pp. 42-47. 
${ }^{25}$ Daniel Pedro Müller, op. cit., p. 251; Jaelson Bitran Trindade \& João Urban, Tropeiros, São Paulo: Editoração Publicações e Comunicações Ltda., 1992, p. 79.

${ }^{26}$ Manuel Eufrásio de Azevedo Marques, Apontamentos históricos, geográficos, biográficos, estatísticos e noticiosos da Província de São Paulo (1879). São Paulo: Edusp/Itatiaia, 1980, vol. 1, pp. 34-35; vol. 2, pp. 51-52.

${ }^{27}$ Auguste de Saint-Hilaire, op. cit., pp. 34-37; Marina Lourdes Ritter, A sociedade nos Campos de Curitiba na época da Independência, Porto Alegre: BRDE, 1982, p. 63.

${ }^{28}$ Auguste de Saint-Hilaire, op. cit., pp. 38-39.

\section{Resumo}

A pecuária foi uma atividade econômica de importância central na formação dos mercados internos coloniais brasileiros. As fazendas cresceram e se fortaleceram na retaguarda dos setores de exportação. $\mathrm{O}$ presente artigo analisa as fazendas de gado existentes no Paraná em 1825, discutindo o emprego da mão-de-obra escrava, familiar e livre, bem como a composição dos rebanhos e a produção de alimentos no seu interior. Os fazendeiros aparecem, nessa conjuntura, como a classe mais poderosa e a principal detentora de terras e escravos.

Palavras-chave: Fazendas de gado, escravidão, Paraná.

\section{Abstract}

The livestock was an economic activity of central importance in the formation of the Brazilian colonial internal markets. The farms grew and they strengthened in the rearguard of the export sectors. The present article analyzes the cattle farms existent in Paraná in 1825, discussing the employment of the slave, family and free labor, as well as the composition of the flocks and the production of victuals in its interior. The farmers appear, in that conjuncture, as the most powerful class and the main owners of lands and slaves.

Key Words: Cattle farms, Slavery, Paraná. 